Paper for Presentation at the Symposium on Radiation Measurements and Applications, Ann Arbor, Michigan, May 12-14, 1998.

*Fluid Transfer Concentration of Airborne Radioxenon to Enhance Monitoring Capabilities

W. R. Russ and J. D. Valentine University of Cincinnati Department of MINE

Cincinnati, OH 45221-0072

and

B. D. Rooney and K. C. Gross

Reactor Analysis Division

Argonne National Laboratory

9700 S. Cass Avenue

Argonne, Il 60439-4842

The submitted manuscript has been created by the University of Chicago as Operator of Argonne

National Laboratory ("Argonne") under Contract No.

W-31-109.ENG-38 with the U.S. Department of

Energy. The U.S. Government retains for itself, and

others acting on its behalf, a paid-up, non-exclusive. irrevocable worldwide license in said article to reproduce prepare derivative works, distribute copies

to the public, and perform publicly and display publicly, by or on behalf of the Government.

*Work supported by the U.S. Department of Energy, Nuclear Energy Programs under Contract W-31-109-ENG-38. 


\section{DISCLAIMER}

This report was prepared as an account of work sponsored by an agency of the United States Government. Neither the United States Government nor any agency thereof, nor any of their employees, make any warranty, express or implied, or assumes any legal liability or responsibility for the accuracy, completeness, or usefulness of any information, apparatus, product, or process disclosed, or represents that its use would not infringe privately owned rights. Reference herein to any specific commercial product, process, or service by trade name, trademark, manufacturer, or otherwise does not necessarily constitute or imply its endorsement, recommendation, or favoring by the United States Government or any agency thereof. The views and opinions of authors expressed herein do not necessarily state or reflect those of the United States Government or any agency thereof. 


\section{DISCLAIMER}

Portions of this document may be illegible in electronic image products. Images are produced from the best available original document. 


\title{
Fluid Transfer Concentration of Airborne Radioxenon to Enhance Monitoring Capabilities
}

W. R. Russ and J. D. Valentine, Department of MINE, University of Cincinnati, Cincinnati, Ohio 45221 B. D. Rooncy and K. C. Gross, Argonne National Laboratory, Argonne, Illinois 60439-4842.

\begin{abstract}
\end{abstract}
To facilitatc airborne radioxenon monitoring, a xenon concentration method with potential advantages over current technology in simplicity, siec, and cost has been developed. The concentration technique is bused on the prefercntial absorption of heavy noble gases (krypton, xenon, and radon) by certain organic fluids. To implement this concentration tochnique, a radioxenon moniloring system requires threc integrated sub-systems: 1) an absorption sub-system; 2) a degassing sub-system; and 3) a radiation detection sub-system. This study is focused on the charactcrization and optimization of the first two sub-systems. Measurements using a small prototype absoption tower have indicalcd a xenon removal factor of approximately 50\% and the spocific concentration at saturation of certain organic nluids to be about 2.5 times the specific concentration in the sampled air. Various tochniques for degassing have been investigated, including heating, purging, agitation and vacuum. Ultrasonic agitation of a thin film in a strong vacuum has been shown to be an effective means of degassing the transfer fluid continuously. Various schemes for integrating all of the sub-systems are considered. Combining the small prototype absorption and degassing sub-systems should result in a transfer efficiency of about $33 \%$ and a single stage concentration fuctor of aboul 6.7.

\section{Introduction}

Atmospheric radioxenon is a primary indicator of the presence of a fission process. The type of source, typically an operating reactor or a nuclear weapons lest, and the distance from the source to the detection system can be determined by measuring the ratios of radioxenon isotopes. However, detcting ambient radioxcnon is complicatod by relatively short half-lives and low atmospheric concentrations. The four isotopes of interest. ${ }^{131 m} \mathrm{Xe}$. ${ }^{135} \mathrm{Xe}^{13 \times m} \mathrm{Xe}$, and ${ }^{133} \mathrm{Xe}$, have half-lives ranging from 9.1 hours to 11.9 days. With limited time to accurately and 
preciscly detect these isotopes, an ambient zenon detection system should be able to perform measurements dircolly in the ficld. In addition, the system must be quite sensilive to the low concentrations present in the atonosphcre, with specific activities on the order of tens of $\mathrm{mBq}$ per cubic meter. One method to enhance the sensitivity of a detection system is the extraction and concentration of radioxenon from large atmospheric samples. Relating the specific activities of these samples back to the volume of processed air would indicate actual concentration. Cursent technology wo concentrate radioxenon primarily consists of cryogenic charcoal absorption [1]. This sludy develops an alternative means of concentrating ambient radioxenon based on a fluid transfer technique.

Fluid transfer concentration uses the affinity that cerain organic fluids have for heavy noble gases (brypton. xenon and sadon) to preferentially absorb these gases in the fluid. Subsequent degassing relcases the absorbed heavy noble gases without the dilution of less soluble atmospheric gases. This concentration system consists of two sub-systems: 1) the absorption sub-system, and 2) the degassing sub-system. The overall radioxenon monitoring system consists of these two sub-systems integrated with a radiation detection sub-system, such that concentration and quantification are oplimized. In this study, characterization and optimization of the concentration sub-systems will be addressed. Previous studies have evaluated the absorption properties of various arganic fluids [2,3]. Coen oil was used with the sub-system prototypes in this study because of its relatively good performance, environmentally benign characteristics, and low cosi.

\section{Absorption}

A cross-current absorption tower, as shown in Figure 1, was used to characterize heavy noble gas absorption by the organic fluid. A similar absorption tower design was used in prcliminary characterization experiments [2]. The absorption tower used in this study was limited 10 about $50 \mathrm{~cm}$ in height because of fume hood restrictions, with a packed bed length of approximately $35 \mathrm{~cm}$. Fluid was pumped into the top of the tower and then flowed down through the packed bed into the fluid reservoir. Air was pumped into a diffuser in the fluid reservoir and then flowed up through the packed bed. The packed bod consisted of $0.635 \mathrm{~cm} \times 0.635 \mathrm{~cm}$ cut polyethylene tubing. 
Insoluble gases wcre released via the air oudet in the upper plenum. This absorption tower was used to measure the xenon removal factor of the absorption wwer and the xenon concentration factor of the fluid.

The xenon removal factor is a measure of the fraction of xenon removed from a spiked air sample after passing through the absorption tower one time. To characterize removal factor, the once-through absorption sub-system, shown in Figure 2, was usod. Various fluid and air flow rates were tested. Results indicate litule dependence on fluid flow rate, but a stronger dependence on air flow rate and input xenon concentration. The best removal factor was approximately $50 \%$ with fluid now of $0.25 \mathrm{lpm}$, air flow of $0.2 \mathrm{lpm}$ and input ${ }^{133}$ Xe concentracion of 6.29 $\mathrm{MBq} / \mathrm{m}^{3}$. The removal factar improves with lower air flow rates, lower inpul radioxenon concentrations and a greater length of packed bed.

The xenon concentration factor has ben defined as the ralio of specific activity from absorbed radioxcron in sawrated fluid to the specific radioxenon activity in the surrounding air. The concentration factor is not dependent on flow rates because it is delermined at equilibrium saturation conditions. It also seems to be fairly independent of the input radioxenon concentration. For com oil, the measured concentration factor was about 2.4 for 54.39 $\mathrm{MBq} / \mathrm{m}^{3}$ of ${ }^{133} \mathrm{Xe}$ in surrounding air and about 2.5 for $36.11 \mathrm{MBq} / \mathrm{m}^{3}$ of ${ }^{133} \mathrm{Xe}$ in surrounding air.

\section{Degassing}

Removing the sbsorbed gas from the host fluid can be accomplished with a varicly of techniques. Each method was evaluated for encrgy and time requirements and dilution of the degas product. Although the absarption mechanism is not fully understood, experiments seem to indicate that in addition to overcoming the standard desorption process dictated by partial pressures per Henry's law, a capture mochanism must also be overcome to cause degassing. Some sort of agitation, thermal or mechanical, could be used to relcasc weakly trapped heavy noble gasses. Enhancing diffusional mass transfer out of the fluid could be accomplished through entrainment with a purge gas $\alpha$ by using a vacuum. Consequently, methods that have heen investigated include heating, bubbling with a purge gas, ulurasonic agitation, vacuum and combinations thercor. These degassing techniques were 
characterized using batches of fluid which had previously been passed through the absorption tower and thus contrincd absorbed radioxenon.

Experimental results wherc only heating was used to degas the fluid indicate that a complete degas would require about one hour with an approximately constant degas rate once the fluid temperature was above about $60^{\circ} \mathrm{C}$. Consequently, the time and energy requirements were considered excessive for a continuously operating system. although heating would not dilute the degas product. While heating may effectivcly overcome the capture mechanism, it did no sufficiently drive desorption.

While bubbling with a purge gas in an open loop system was observed to be a relatively efficient degassing technique, the resulting dilution renders this technique ineffective for concentration purposes. Bubbling a purge gas through the fluid in a closed loop system was relatively ineffective, probably because of reabsorption in the fluid. Nonethcless, these air sparging results indicate that the mechanical agitation of bubbling combined with desorption-driving entrainment could be effective if replaced with less diluting methods.

To confirm that ultrasonic agitation would degas the fluid, a sonic disrupter was submerged about $3 \mathrm{~cm}$ doep in a beaker with $100 \mathrm{ml}$ of fluid. Activity was monitorod using a $5 \mathrm{~cm} \times 5 \mathrm{~cm} \mathrm{NaI(TI)} \mathrm{deloctor} \mathrm{and} \mathrm{temperature} \mathrm{was}$ monitored to verify any thermal cffocts. Results indicate that sonic agitation by jtself is slow, with a complete degas requiring over 30 minutes for the $100 \mathrm{ml}$, at which point heating also became a faclor. Nonetheless, cavitation and agitation were very evident, suggesting that ultrasonic agitation might be effective when combined with a technique to enhance desorption.

Vacuum was tested with $300 \mathrm{ml}$ of fluid in a vacuum chamber. Activity was monitorod using a $5 \mathrm{~cm} \times 5 \mathrm{~cm}$ $\mathrm{NaI}(\mathrm{Tl})$ deiector. Results indicate very little degas with the $72 \mathrm{~cm} \mathrm{Hg}$ vacuum alone. While the vacuum was creating a strong pressure gradicnt to drive desorption, therc was no accompanying agitation. A magnetic stirrer was added to provide the agitation. A complete degas was realized in about 20 minulcs afler the magnecic stirrer was started and created some cavitating agitation. Further tosts demonstrated that a thinner layer of fluid in the botion of the vacuum chambcr also increased degassing efficiency. This suggested that creating a thin film of the Auid, perhaps with a packed bed. would also enhance degassing. Aside from lcakage, the vacuum technique does no dilute the degas product. 
Using the results of the previous batch experiments. a proxaype degassing sub-system was constructed for continuous flow experiments. This protolype combines a strong vacuum with a sonic distupter housed in a flow cell that drains into an $20 \mathrm{~cm}$ packed bod, thin film tower. This vacuum chamber design, shown in Figure 3, was tested with $200 \mathrm{ml}$ of fluid at 0.1 liters per minutc continuous flow. After passing through the degassing chamber once, the sample was degassed $66.7 \pm 3.2 \%$ with little heating $\alpha$ dilution. To optimize the degassing sub-system, a longer packed bed and multiple stages could be incorparated. Increasing the diameter of the chamber from the $5 \mathrm{~cm}$ diameter prototype would also minimize flooding that limits the flow rate to about $0.1 \mathrm{lpm}$.

\section{System Integration}

Given an optimized absoption tower and degassing chumber, these sub-systems must be integrated and optimized in a way that most effectively concentrales xenon for subsequent deloction. Three potential concentration schemes are single pass, holdup and recirculation. All of these schemes consist of a continuous loop of absorption Auid being pumped between the abscrption towcr and the degassing chamber while air is pumped through the absaption towcr. The schemes differ in the treatment of the degas product drawn off by the vacuum pump. The single pass system simply passes the degas product through the detection sub-system prior to venting. The holdup system retains the degas product in a chamber placed in front of the detector, with pressure increasing in this chamber over time. The rocirculation system passes the degas product through the detoction sub-system prior to combining it with air entering the absorption cower. The holdup system has the advantage of retaining the most dcgas product in the detection sub-system for the greatest amount of time. However, since any source chamber and vacuum pump have a limilod pressure capacity, excess degas product must be vented. Venting excess degas product to the atmosphere, as in the single pass system. Tesults in the system concentration factor of:

$$
\frac{C_{d z}}{C_{\text {dir }}}=\varepsilon_{\text {tres }} \frac{R_{\text {air }}}{R_{\alpha z}}
$$

where $\mathrm{C}_{d y}$ is the specific radioxenon concentration in the degas product, $\mathrm{ml}^{-1}$, $\mathrm{C}_{\mathrm{air}}$ is the specific radioxenon concentration in the input air, $\mathrm{ml}^{-3}$, 
$R_{\text {w }}$ is the volumetric flow rate of input air, $\mathrm{mL}$.

$R_{\text {deq }}$ is the volumctric flow rate of degas product, $\mathrm{ml} / \mathrm{s}$, and

Ene is the transfer efficiency: input Xe atoms per unit time/degassed Xe atoms per unit time.

However, if the excess degas product is recirculated back into the concentration system via a pressure relicf valve as shown in Figure 4, the system concentration factor is improved. The differential equation defining the dynamic concentration of the recirculation system is given by:

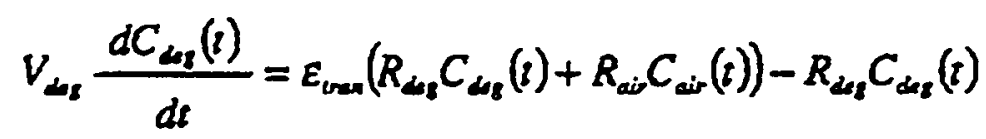

where Vdeg is the tonl volume occupied by the degas product (mi).

The general solution for this differential equation is given by:

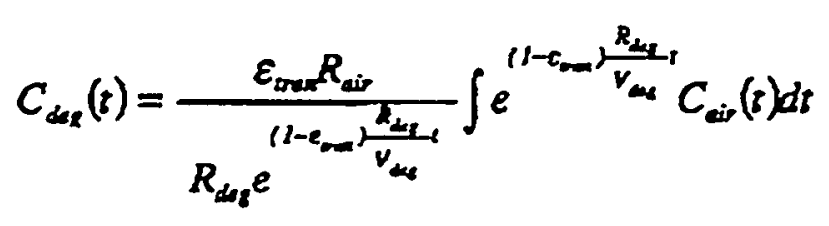

The system concentration factor for the recirculation system in steady state is given by:

$$
\frac{C_{\text {dg }}}{C_{\text {air }}}=\frac{\varepsilon_{\text {srar }}}{1-\varepsilon_{\text {tran }}} \frac{R_{\text {air }}}{R_{\text {dg }}}
$$

This steady state solution shows an improvement factor over the single pass system of $1 /\left(1-E_{1-z}\right)$. Of course, $n$ multiple stages of concentration systems would yield a concentration factor of $\left(C_{\text {sog }} / C_{d}\right)^{*}$, limiled only by the number of stages. However, to minimize the number of stages requircd, cach stage must be optimized.

\section{Cunclusions}

The absorption tower characterized in this study absorbs about half of the radioxenon contained in input air. A fleldable absorption tower, not limited $1050 \mathrm{~cm}$ in height or to a single tower, should absorb a greater percentage 
percentage $(>90 \%)$ with a greater air flow sate [4]. The degassing sub-system characterized in this study demonstratcd the ability to degas about $67 \%$ of the absorbed xenon continuously. A fieldable degassing unit consisting of several stages should also be able to improve on the percentage of xenon degassed. However, given only the testad laboratory scale units, approximately one third of the xenon contained in the input air will be cransferred inco the detection sub-system by the fluid. With mcasured input and degassing air flow rates of $4.0 \mathrm{lpm}$ and $0.03 \mathrm{lpm}$, respectively, and a 33\% transfer efliciency, the minimum system concentration factor for an unpressurized, recirculating source cell is about 6.7 for a single stage.

Fluid transfer concentration of radiaxenon has polential advantages in simplicity, size and cost relative to curent cryogenic distillation systems. Since the fluid transfer concentration system will also concentrate fadon, the integrated system must be able to distinguish radon. Radon discrimination can be accomplished using pulse processing cechniques [S], o possibly by fractionation of the xenon and radon in the degassing sub-system of the concentration system. Further study will include more oplimization of the protolype concentration sub-systems, empirical characterication of the integralcd concentration system, radon discrimination, and monitoring system calibration.

\section{Acknowledgements}

This work was supported in part by the U.S. Department of Energy under grant no. DE-FG07-97ER62521 and in part by the U.S. Defensc Spocial Weapons Agency under grant no. DSWA01-97-1-0027.

\section{References}

[1] P. Rcoder and T. Bowyer, "High Sensitivity Detection of ${ }^{133} \mathrm{Xe}$ via Dclayed Coincidence Counting," Pacific Northwest National Loboratories, Richland, Washinglon, 1997.

[21 K. V. Liu, J. D. Gabor, K. C. Gross, and R. E. Holz, "Fluid-Based Radon Mitigation Technology Development for Decontamination and Decomissioning," procsedings of the fourth international Conference on Nuclear Engincering, New Orleans, Lovisiana, 10-14 March 1996. 
[3] M. Stcinberg and B. Manowilz. “An Absorption Process for Recovery of Fission Product Noble Gases." BNL 493 (T-115), Feb. 1958.

[4] K.V. Liu, J.D. Gabor, R.E. Holk., and K.C. Gross, "Fluid-Based Radon Mitigation Technology Development for Industrial Applicutions," Proc. 1996 Chinese American Academic and Professional Conference., Otawa, Canada (June 29 - July 2. 1996).

[5] W. R. Russ, D. O. Stuenkel, J. D. Valentine, and K. C. Gross, "An Evaluation of Radioxenon Detection Techniques for use with a Fluid-Based Concentration System" submitred for presentation at the 1998 IEEE Nuclear Science Symposium. Toronto, Canada. November 1998 


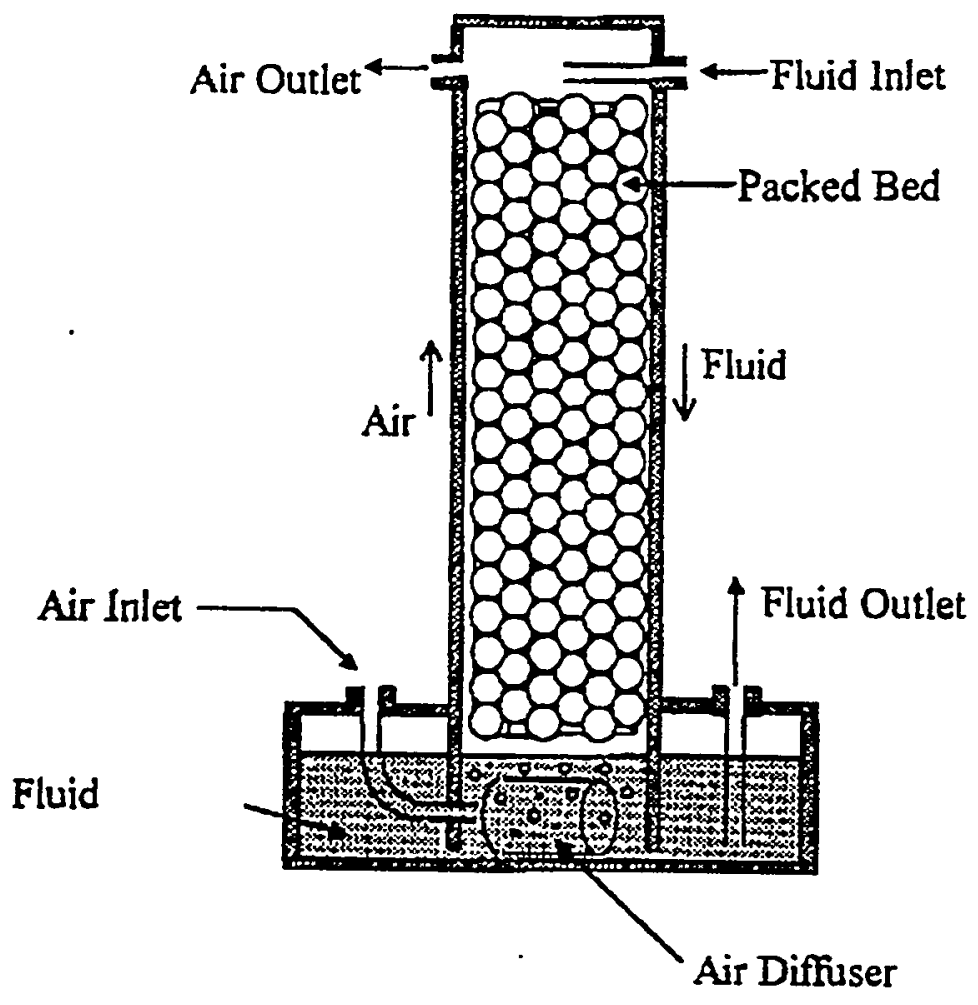

Figure 1 - Schematic of an absorption tower used to transfer xenon from the air to an organic fluid.

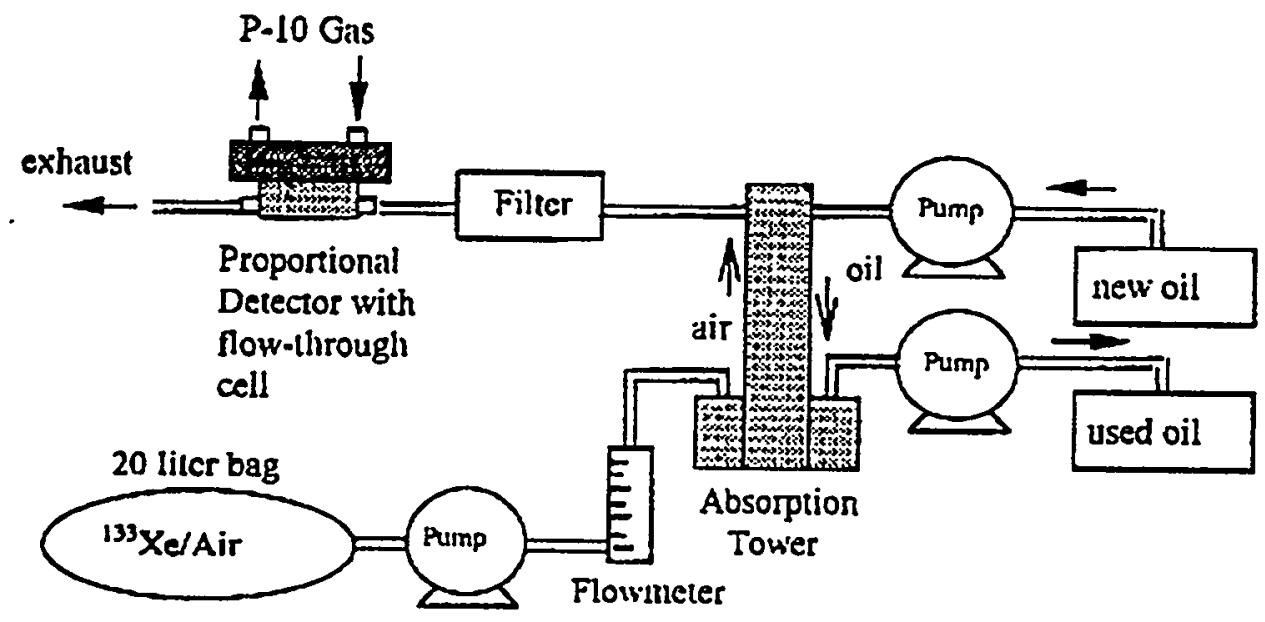

Figure 2 - Experimental configuration for measuring xenon removal factor of the prototype absorption tower. 


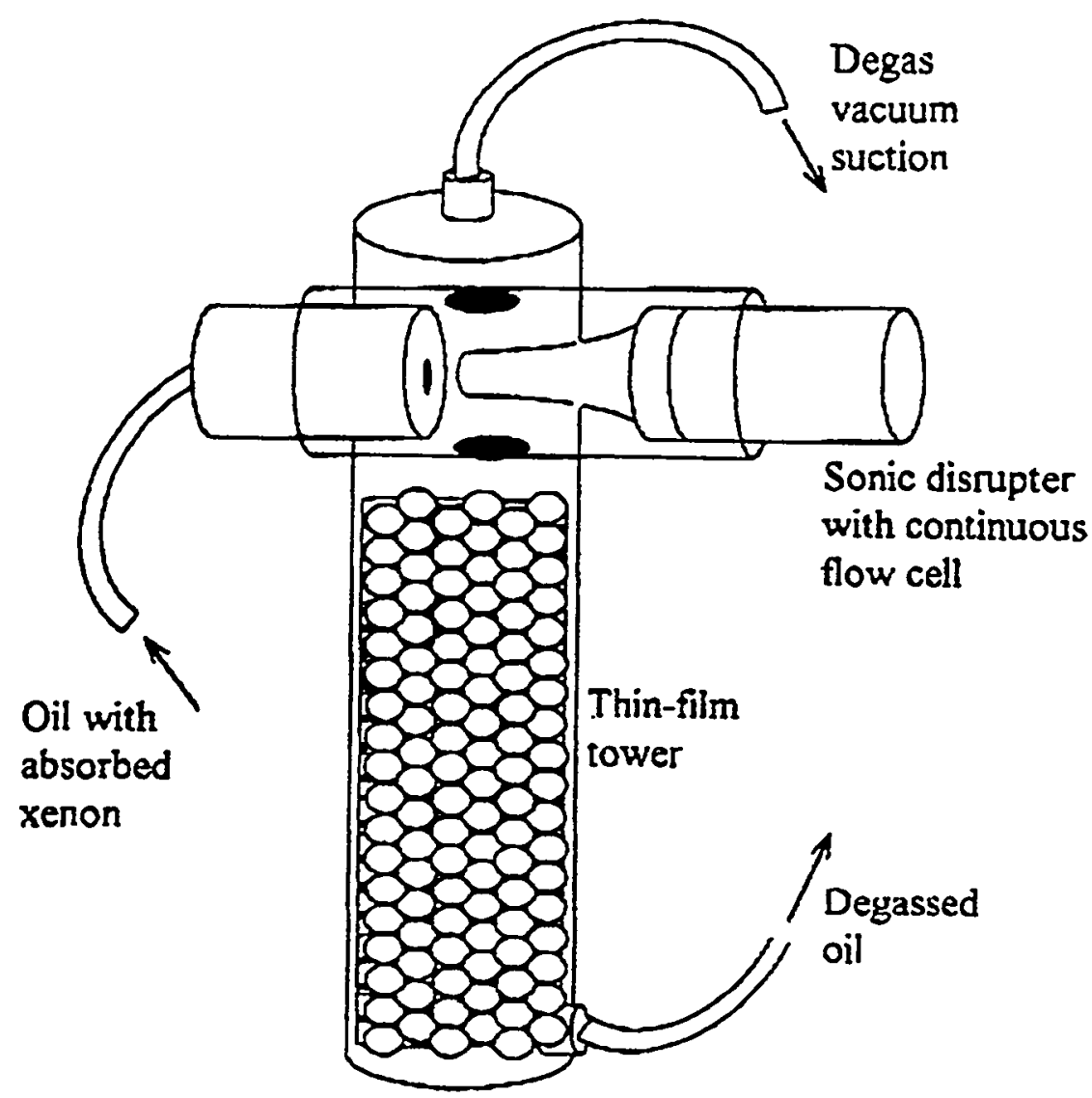

Figure 3 - Diagram of the degassing chamber constructed as a combination of sonic agitation with strong vacuum and thin-film tower with a strong vacuum.

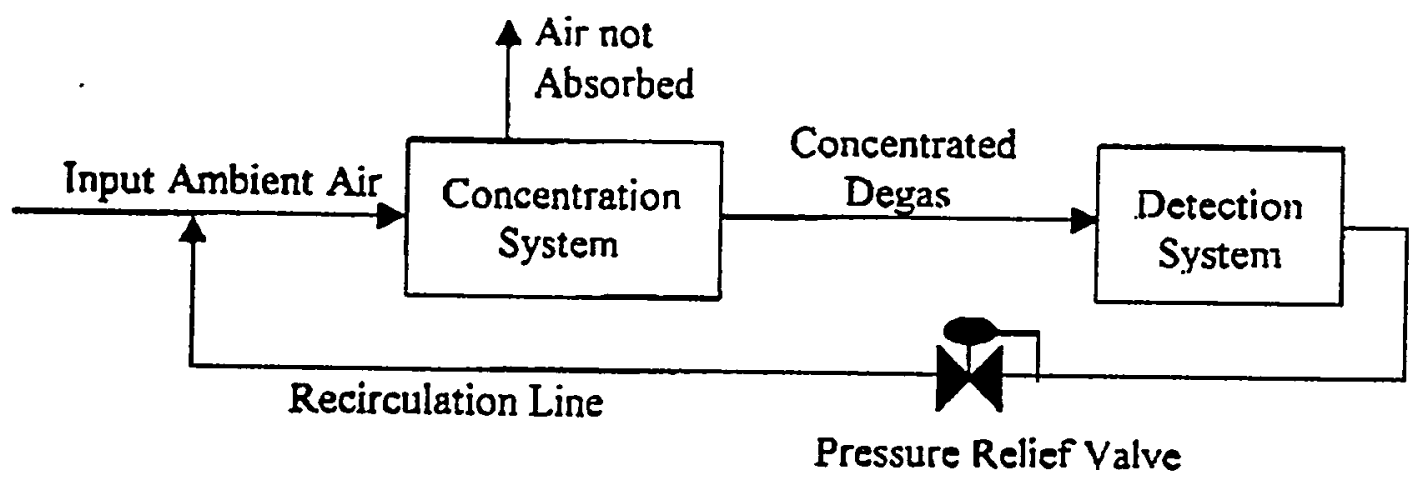

Figure 4-Simplified schematic of combined holdup and recirculation scheme for system integration. 